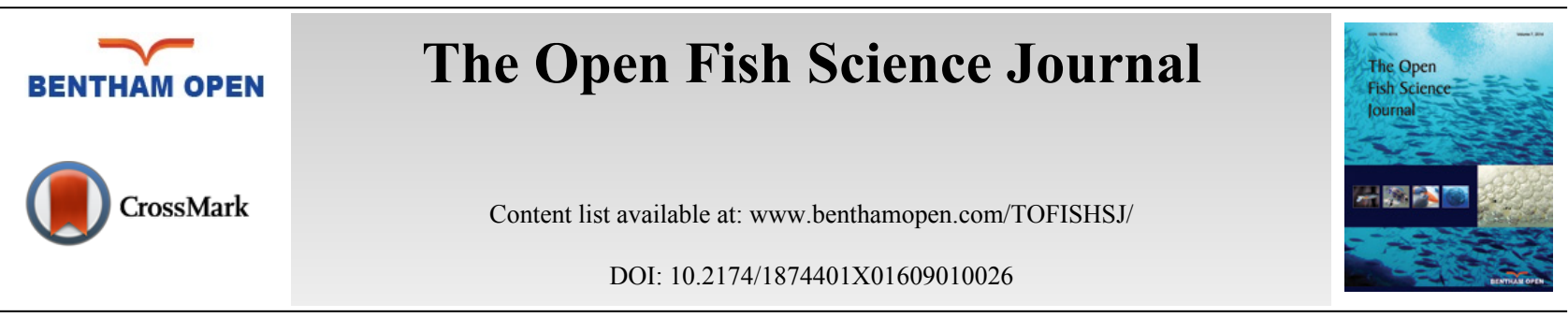

\title{
Rapid Lateral Extraction of Otoliths that Maintains the Integrity of Fish Product to Improve Access to Catches and Reduce Potential Sampling Biases
}

\author{
Corey B. Wakefield ${ }^{1,2,}$, Dion K. Boddington ${ }^{1,2}$ and Stephen J. Newman ${ }^{1,2}$ \\ ${ }^{I}$ Western Australian Fisheries and Marine Research Laboratories, Department of Fisheries, Government of Western \\ Australia, P.O. Box 20, North Beach, Western Australia, 6920, Australia \\ ${ }^{2}$ Department of Environment and Agriculture, Curtin University, Bentley, Western Australia, 6845, Australia
}

Received: October 08, 2015

Revised: April 12, 2016

Accepted: April 12, 2016

\begin{abstract}
The capacity to sample otoliths of fish from commercial, recreational, artisanal or subsistence catches can be constrained if the dissection process results in alterations to their external appearance and thus reduces its value and/or shelf life. There can also be significant biases incorporated into the collection of otolith samples if access is only granted relative to the size of the fish (i.e. if smaller fish are sold whole). To reduce such limitations, we herein describe a rapid and simple method of lateral otolith extraction that maintains the integrity of the fish product, and thus reduces potential biases in sample collection for age structure data. Representative sampling is an important consideration for the collection of age structure data when it is intended to be used in fisheries stock assessments.
\end{abstract}

Keywords: Age Data, Fisheries, Representative Sampling, Sagittal Otolith Removal.

Sagittal otoliths of fish are currently regarded as the primary structure for obtaining reliable estimates of their age [1]. Deriving estimates of mortality from age structure data for an exploited population of fish is an integral part of determining their sustainable harvest through quantitative stock assessments. To improve the accuracy of stock assessment estimates it is vital that the collection of age structure data be representative of the temporal and spatial distribution of fishing catch and/or effort. Considering fish population monitoring studies are usually constrained by funding and resources, collections of otoliths rely on the assistance of fishers to allow scientists to perform fish dissections on their valued catches. Such access is often restricted due to the sampling process resulting in alterations to the fish's external appearance and/or exposing internal structures to the external environment, subsequently reducing their value and shelf life (e.g. [2]). In order to reduce bias in age structure data during sampling access to catches needs to be maximised. This can be achieved through a rapid technique of otolith extraction that maintains the appearance and quality of sampled fish, which would thus overcome many factors that may prevent access for dissections prior to sizebased grading (e.g. filleting of larger fish, selling of smaller fish whole), which reduces the potential for sampling bias.

Sagittal otoliths are located within the otic capsule that forms the ventral, posterior portion of the cranium. The otic capsule is made up predominantly of the exoccipital, basioccipital and parasphenoid bones (Fig. 1b). Sagittal otoliths are most commonly extracted either 1) dorsally by opening the cranium using a sawing device, or 2) ventrally by removing the gills to expose the otic capsule which can be levered opened using bone cutters or scissors (Fig. 1), [3]. However, both these extraction methods require significant alterations to the physical appearance of the fish, which can reduce the value of the fish and subsequently limit access to catches for scientific dissections.

\footnotetext{
* Address correspondence to this author at the Western Australian Fisheries and Marine Research Laboratories, Department of Fisheries, Government of Western Australia, P.O. Box 20, North Beach, Western Australia, 6920, Australia; Tel: +61-8-9203-0111; Fax: +61-8-9203-0199; E-mail: Corey.Wakefield@fish.wa.gov.au
} 

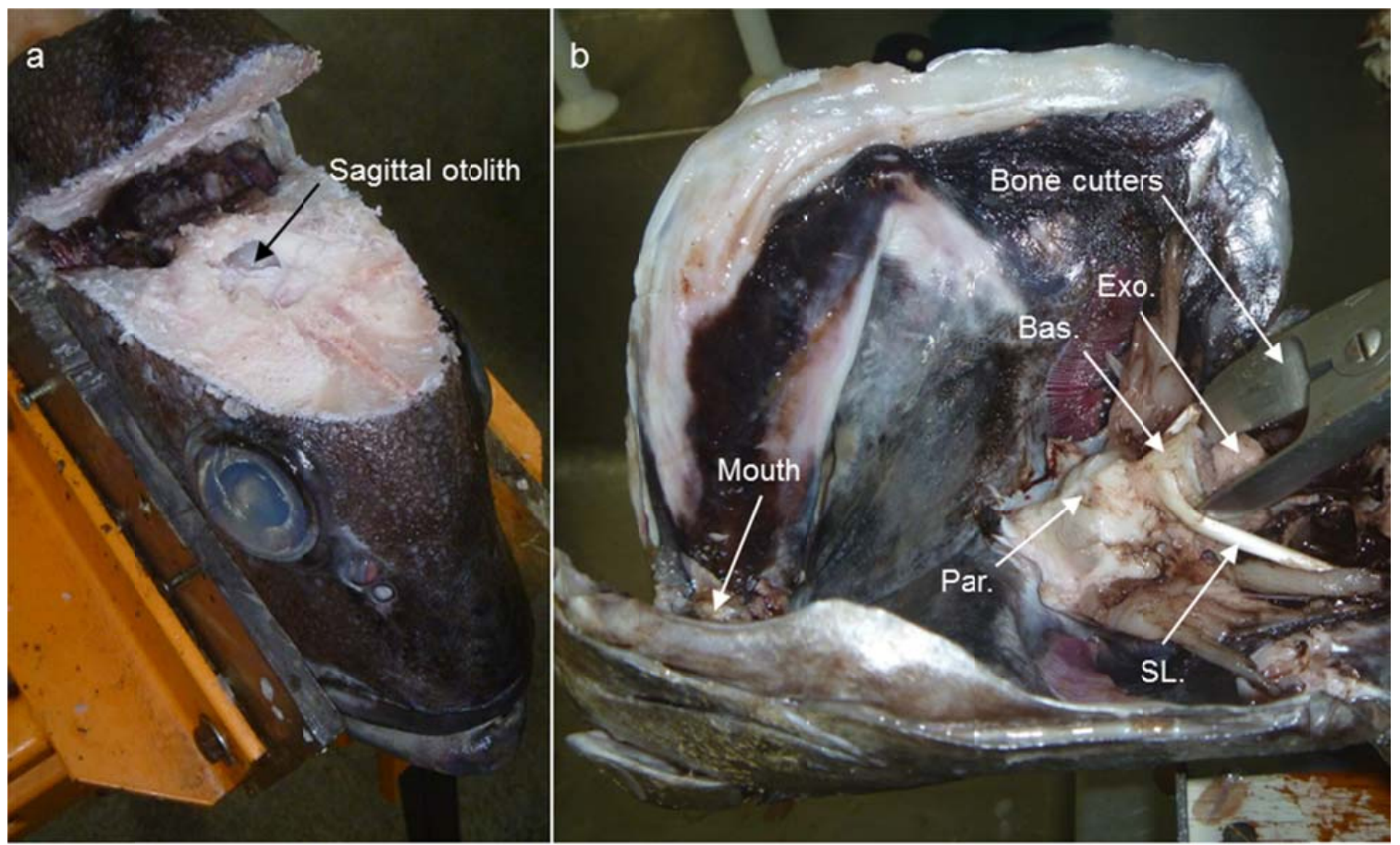

Fig. (1). (a) Dorsal extraction of sagittal otoliths of a Glaucosoma herbraicum through an incision that opens the top of the head at the base of the nape above the eyes. (b) Ventral extraction of sagittal otoliths of a Glaucosoma herbraicum at the base of the cranium (anterior to left) through the otic capsule (comprised of the exoccipital (Exo.), basioccipital (Bas.) and parasphenoid (Par.) bones) by cutting the suture between the basioccipital and exoccipital bones at about a $45^{\circ}$ angle using bone cutters and levering open. SL subopercular ligament.

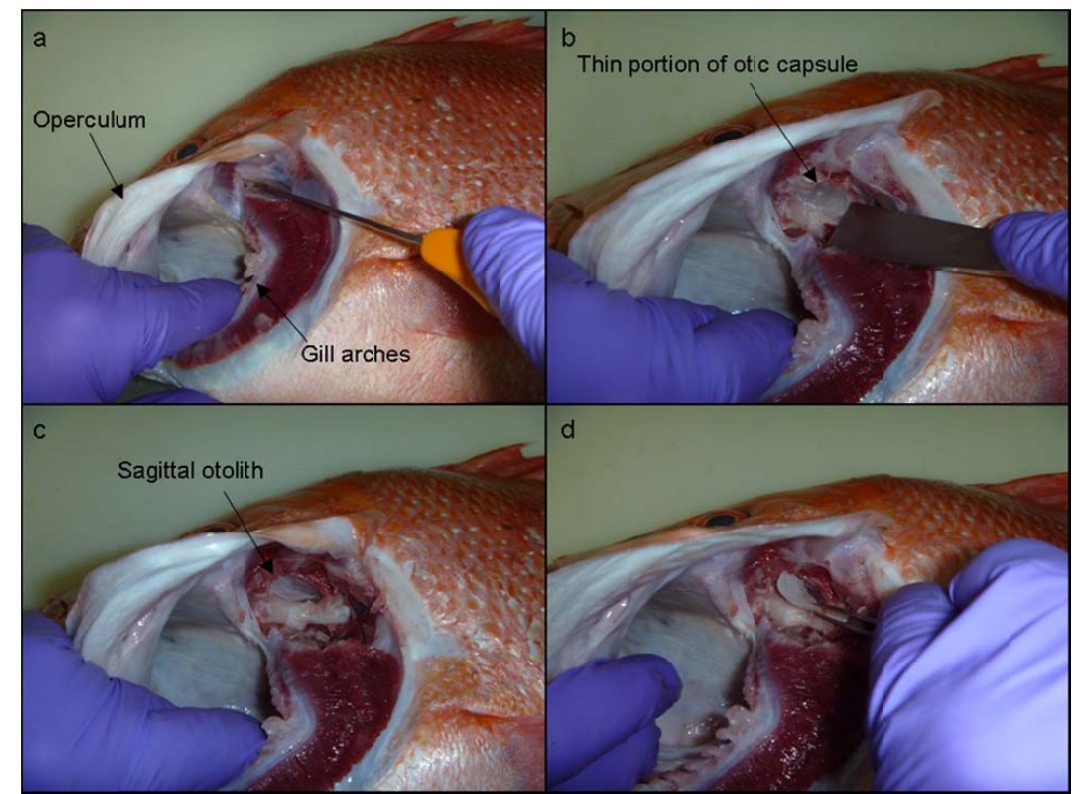

Fig. (2). (a) Lateral extraction of otoliths involving an initial incision at the dorsal junction of the gill arches and parasphenoid process under the operculum of a Lutjanus sebae (2,849 $\mathrm{g}$ whole weight, $570 \mathrm{~mm}$ total and $532 \mathrm{~mm}$ fork length); (b) using a chisel to shave off the thin lateral portion of the basioccipital bone of the otic capsule; (c) the left sagittal otolith is visible within the otic capsule; and (d) otolith removed using forceps.

The lateral extraction of sagittal otoliths proposed in this study offers a quick and relatively much less invasive technique, that accesses the otic capsule (i.e. the ventral, posterior portion of the cranium) by going under the operculum. A headlamp is recommended to illuminate the gill cavity underneath the operculum. A small incision is 
made through the cartilage at the dorsal junction of the first few gill arches and the parasphenoid process (Fig. 2a). These first few gill arches can then be shifted aside slightly and a knife/chisel used to scrape away the membranous tissue to expose the lateral aspect of the otic capsule (Fig. 2b). With the tip of a surgical-grade chisel (generally 20-25 mm blade width) the lateral portion of the basioccipital bone of the otic capsule can be shaved off (Fig. 2b). This lateral portion of the basioccipital bone is relatively thin in most fish and can generally be shaved off with little effort. Once this portion of bone is removed the sagittal otolith is obvious (Fig. 2c) and easily accessed and removed using forceps (Fig. 2d).

This technique of lateral otolith extraction, once perfected, can be performed rapidly (i.e. $<1$ minute per fish). For example, otolith extractions for 30 Lutjanus sebae were completed in 22 minutes onboard a research cruise in 2011. The time required to train staff in this technique has been minimal ( $<2$ hours), based on a single session held at two separate for fish ageing workshops where participants successfully learnt on a range of predominantly lutjanid species (e.g. [4]). This method has also been used on a large size range of fish, i.e. juveniles $<200 \mathrm{~mm}$ total length (TL) such as Epinephelus multinotatus, Lutjanus vitta and Lethrinus punctulatus (CB Wakefield pers. comm. 2011) and large deepwater species up to $1200 \mathrm{~mm}$ TL such as Hyporthodus octofasciatus (e.g. [5]) and Etelis spp (e.g. [6]). This technique is now commonly used to improve representative sampling (i.e. prior to size-based grading by processing markets) for many Lutjanidae, Epinephelidae and Lethrinidae species that contribute toward age-based stock assessments in Western Australia.

\section{CONFLICT OF INTEREST}

The authors confirm that this article content has no conflict of interest.

\section{ACKNOWLEDGEMENTS}

Logistic support for this study was provided by the Department of Fisheries (Western Australia). The authors would like to thank Doug Gibson (commercial fisher) and the fish processing staff at Sealanes (Fremantle, Western Australia) for allowing access to fish for dissections.

\section{REFERENCES}

[1] Campana SE. Accuracy, precision and quality control in age determination, including a review of the use and abuse of age validation methods. J Fish Biol 2001; 59: 197-242.

[http://dx.doi.org/10.1111/j.1095-8649.2001.tb00127.x]

[2] Schneidervin RW, Hubert WA. A rapid technique for otolith removal from Salmonoids and Castostomids. N Am J Fish Manage $1986 ; 6$ : 287. [http://dx.doi.org/10.1577/1548-8659(1986)6<287:ARTFOR>2.0.CO;2]

[3] Secor DH, Dean JM, Laban EH. Manual for otolith removal and preparation for microstructural examination: Electric Power Research Institute and Belle W. Columbia, S.C: Baruch Institute for Marine Biology and Coastal Research 1991.

[4] Newman SJ, Wakefield CB, Williams AJ, et al. International workshop on methodological evolution to improve estimates of life history parameters and fisheries management of data-poor deep-water snappers and groupers. Mar Policy 2015; 60: 182-5. [http://dx.doi.org/10.1016/j.marpol.2015.06.020]

[5] Wakefield CB, Newman SJ, Marriott RJ, et al. Contrasting life history characteristics of the eightbar grouper Hyporthodus octofasciatus (Pisces: Epinephelidae) over a large latitudinal range reveals spawning omission at higher latitudes. ICES J Mar Sci 2013 ; 70 : 485-97. [http://dx.doi.org/10.1093/icesjms/fst020]

[6] Wakefield CB, Williams AJ, Newman SJ, et al. Rapid and reliable discrimination for two cryptic Eteline snappers using otolith morphometry. Fish Res 2014; 151: 100-6.

[http://dx.doi.org/10.1016/j.fishres.2013.10.011]

(C) Wakefield et al.; Licensee Bentham Open.

This is an open access article licensed under the terms of the Creative Commons Attribution-Non-Commercial 4.0 International Public License (CC BY-NC 4.0) (https://creativecommons.org/licenses/by-nc/4.0/legalcode), which permits unrestricted, non-commercial use, distribution and reproduction in any medium, provided the work is properly cited. 